\title{
Konsep Desain Eko-Wisata Bahari Tlocor di Sidoarjo, Jawa Timur
}

\author{
Nur Wahyu Adelia Ratih ${ }^{1}$, Wiwik Widyo Widjajanti ${ }^{2}$ \\ ${ }^{1}$ Jurusan Arsitektur, Fakultas Teknik Sipil dan Perencanaan, Institut Teknologi Adhi Tama Surabaya \\ ${ }^{2}$ Jurusan Arsitektur, Fakultas Teknik Sipil dan Perencanaan, Institut Teknologi Adhi Tama Surabaya \\ Email: ${ }^{1}$ nwratihadelia@gmail.com
}

\begin{abstract}
Tourism is one of the largest industrial sectors and is the fastest growing economic sector in the world. Based on this, many developed and developing countries competed in developing tourism objects because they could have a wide-ranging impact, including Indonesia. Indonesia is an archipelago surrounded by territorial waters that has the potential to be developed into a coastal tourism object area. Tourism objects in the coastal area can be an attraction because of its natural beauty. One of them is located in Sidoarjo. Maritime tourism is the main attraction in Sidoarjo not only because of its natural beauty but also quite unique. Where one of them is Wisata Bahari Tlocor, which is located in Telocor, Tanjungsari, Kupang, Jabon Sub-District, Sidoarjo District. Wisata Bahari Tlocor has an island or what is commonly known, Pulau Lusi. Pulau Lusi is an artificial island formed from the Sidoarjo mud deposit which is discharged into the sea by direct disposal through the Sungai Porong. Thus, the title of Tlocor Marine Ecotourism Concept Design was drawn, in Sidoarjo, East Java. In its planning, this Marine Eco-Tourism Design will later use environmental-oriented architectural themes with the concept of creative architecture. The concept of micro ecology which will be applied to land use. The adaptive micro concept of river waters will be used as a concept of building shape, and the concept of micro pragmatic for spatial planning, which will later be the answer to the problems that exist in the building and make visitors more comfortable.
\end{abstract}

Keywords : Maritime, Tourism, Tlocor, a Tour

\begin{abstract}
Abstrak. Pariwisata merupakan salah satu sektor industri terbesar dan menjadi sektor ekonomi yang tumbuh paling cepat di dunia. Berdasarkan hal tersebut banyak negara maju dan berkembang berlombalomba dalam mengembangkan obyek pariwisata karena dapat memberikan dampak yang bersifat luas termasuk Indonesia. Indonesia merupakan negara kepulauan dengan dikelilingi wilayah perairan memiliki potensi untuk dikembangkan menjadi kawasan objek pariwisata pesisir. Obyek pariwisata di kawasan pesisir dapat menjadi daya tarik karena keindahan alamnya. Salah satunya yang berada di Kabupaten Sidoarjo. Wisata bahari yang menjadi daya tarik di Sidoarjo bukan hanya karena keindahan alamnya saja tetapi terbilang juga cukup unik. Dimana salah satunya adalah Wisata Bahari Tlocor, yang berlokasi di Telocor, Tanjungsari, Kupang, Kecamatan Jabon Sidoarjo. Wisata Bahari Tlocor ini didalamnya terdapat pulau atau yang biasa dikenal, Pulau Lusi, Pulau Lusi merupakan pulau buatan yang terbentuk dari endapan lumpur Sidoarjo yang dibuang ke laut dengan proses pembuangan langsung melalui sungai porong. Maka, ditariklah judul Konsep Desain Eko-wisata Bahari Tlocor, di Sidoarjo, Jawa Timur. Dalam perencanaannya, Desain Eko-Wisata Bahari ini nantinya akan menggunakan tema arsitektur berwawasan lingkungan dengan konsep berupa arsitektur rekreatif. Konsep mikro ekologi yang dimana akan diterapkan pada tata lahan. Konsep mikro adaptif dari perairan sungai akan digunakan sebagai konsep bentuk bangunan, dan konsep mikro pragmatik untuk tata ruang, dimana nantinya akan sebagai jawaban dari permasalahan yang ada pada bangunan dan membuat pengunjung lebih nyaman.
\end{abstract}

Kata Kunci : Bahari, Pariwisata, Tlocor, Wisata

\section{Pendahuluan}

Sidoarjo adalah sebuah kabupaten di Provinsi Jawa Timur, Indonesia. Sidoarjo memiliki luas sekitar 591,59 km. Kabupaten ini disebelah utara berbatasan dengan Kota Surabaya dan Kabupaten Gresik, disebelah timur berbatasan dengan Kabupaten Pasuruan dan disebelah selatan berbatan dengan Kabupaten Mojokerto. Bersama dengan Gresik, Sidoarjo merupakan salah satu penyangga utama Kota Surabaya serta termasuk dalam kawasan Gerbangkertosusila (akronim dari Gresik, Bangkalan, 
Mojokerto, Surabaya, Sidoarjo, Lamongan). Sidoarjo bisa dibilang merupakan daerah yang mengalami perkembangan cukup pesat. Keberhasilan ini dicapai karena berbagai potensi yang ada di wilayahnya seperti industri dan perdagangan, pariwisata serta usaha kecil dan menengah yang dikemas dengan baik dan terarah. Dalam hal dibidang kepariwisataan. Wisata yang menjadi daya Tarik di Sidoarjo adalah salah satunya wisata bahari, karena Sidoarjo dikenal sebagai Kota Delta, dimana Kota Sidoarjo berada diantara dua sungai yang besar pecahan Kali Brantas, yaitu sungai Kali Mas dan Kali Porong. Wisata bahari ini yaitu Wisata Bahari Tlocor, yang terletak di Desa Telocor, Tanjungsari, Kec. Jabon, Sidoarjo. Wisata Bahari Tlocor ini didalamnya terdapat pulau atau yang biasa dikenal, Pulau Lusi, Pulau Lusi merupakan pulau buatan yang terbentuk dari endapan lumpur Sidoarjo yang dibuang ke laut dengan proses pembuangan langsung melalui sungai porong. Kawasan Pulau Lusi merupakan salah satu destinasi wisata berwawasan lingkungan (ekowisata) di Kabupaten Sidoarjo yang menyediakan beberapa fasilitas untuk kegiatan konservasi, edukasi, dan rekreasi. Untuk akses menuju pulau ini, wisatawan dapat menggunakan speedboat, dimana dari dermaga Tlocor, wisatawan bisa menuju ke Pulau Lusi.

\subsection{Tinjauan Pustaka}

Arsitektur berwawasan lingkungan adalah tema arsitektur dengan pendekatan arsitektur ramah lingkungan yang menciptakan suatu karya arsitektur yang sangat memperhatikan kaidah - kaidah hubungan antara arsitektur dengan lingkungan. Pada Desain Wisata Bahari Tlocor ini akan mengkorelasikan perancangan yang berhubungan dengan tema arsitektur berwawasan lingkungan dengan tujuan menciptakan suatu wilayah yang ramah dengan lingkungan, bukan hanya wilayah akan tetapi dari semua aspek, baik itu dari tatanan lahan, bentuk, dan ruang. Karena jika dilihat dari fungsi desain ini akan sangat membutuhkan suatu rancangan yang memperhatikan lingkungan sekitar karena dari pengolahan itu sendiri akan sangat membutuhkan wadah yang berkaitan langsung dengan pendekatan tema arsitektur berwawasan lingkungan.

Pengaplikasian pada proses Desain Eko-Wisata Bahari Tlocor, untuk penataan massa bangunan menggunakan pola rancangan kombinasi antara sirkulasi radial, dan kurvalinier. Sistem radial dicirikan dengan adanya titik pusat yang menjadi tujuan atau asal pergerakan. Sistem kurvalinier merupakan gabungan dari pola garis lurus dan garis lengkung, yang memanfaatkan topografi dengan cara mengikuti bentuk lahan.

\subsection{Metode Penelitian}

Dalam penelitian ini menggunakan jenis penelitian kualitatif, karena penulis mencoba melihat, mengamati dan menelaah obyek Wisata Bahari Tlocor yang terletak di Sidoarjo. Dimana metode yang dipakai untuk mendukung dalam penelitian ini yaitu: (1) Metode Interview, dengan melakukan wawancara terhadap beberapa pengunjung, pengelola wisata ini maupun penduduk sekitar sehingga didapatkanlah informasi dari berbagai sumber kalangan yang berbeda; (2) Metode Analisa Data, guna menganalisis setiap data yang sudah didapat, dalam menganalisa studi kasus literatur maupun studi kasus lapangan; (3) Metode Dokumenter melingkupi kegiatan peneliti dalam rangka mengumpulkan data dengan cara mendokumentasikan informasi-informasi yang terkait dengan laporan ini guna untuk mendukung maupun menjawan semua permasalahan - permasalahan pada laporan konsep ini.

\section{Pembahasan}

Pembahasan ini berisi muatan mengenai proses perencanaan konsep desain, mulai dari penarikan objek studi banding, telaah terhadap lokasi desain, penyusunan konsep desain, hingga gambaran hasil konsep desain dari Eko-Wisata Bahari Tlocor.

\subsection{Studi Banding}

Hasil observasi studi banding disini merupakan studi banding lapangan dan literatur. Dimana studi banding lapangan mengambil objek Pantai Balekambang yang berlokasi di Dusun Sumber Jambe, Desa Srigonco, Kec. Bantur, Malang, Jawa Timur dan Pantai Goa Cina yang berlokasi di Tambak, Sitiarjo, Sumbermanjing, Malang, Jawa Timur. Untuk studi banding literatur mengambil objek Pantai Gili Trawangan yang berlokasi di Gili Trawangan, Gili Indah, Kabupaten Lombok Utara, Nusa 
Tenggara Barat dan Tanjung Benoa di Kuta Selatan, Bali. Alasan pemilihan objek-objek studi banding ini dikarenakan adanya kemiripan dengan objek penelitian yaitu dimana adanya pulau di sekitar objek.

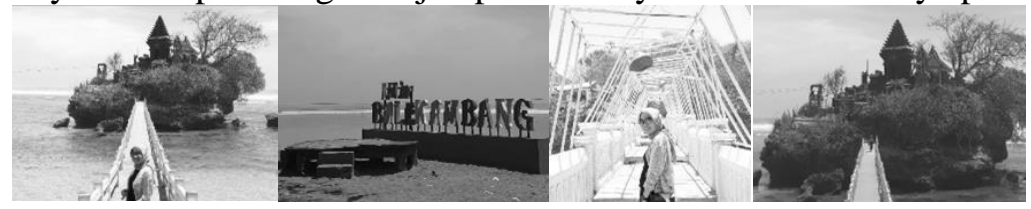

Gambar 1. Pantai Balekambang, Malang-Jawa Timur

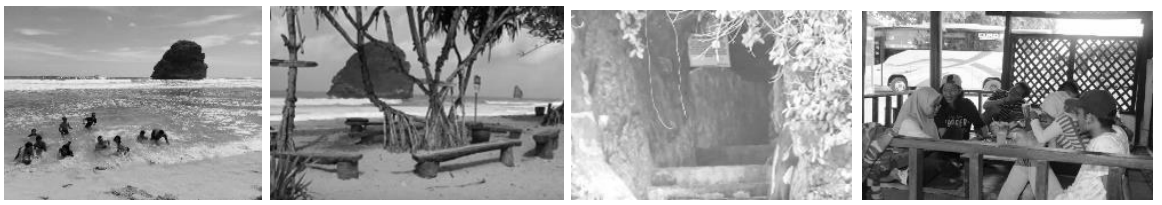

Gambar 2. Pantai Goa Cina, Malang-Jawa Timur

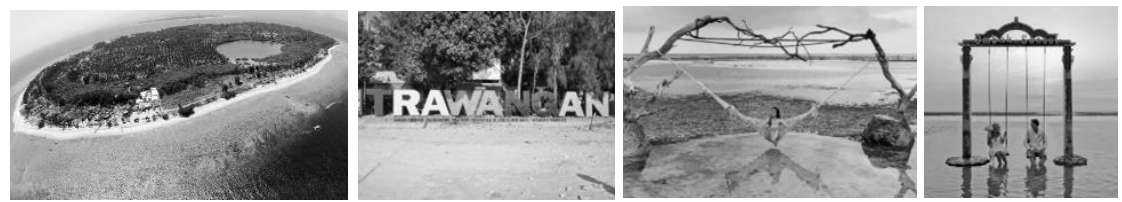

Gambar 3. Pantai Gili Trawangan, Lombok-Nusa Tenggara Barat

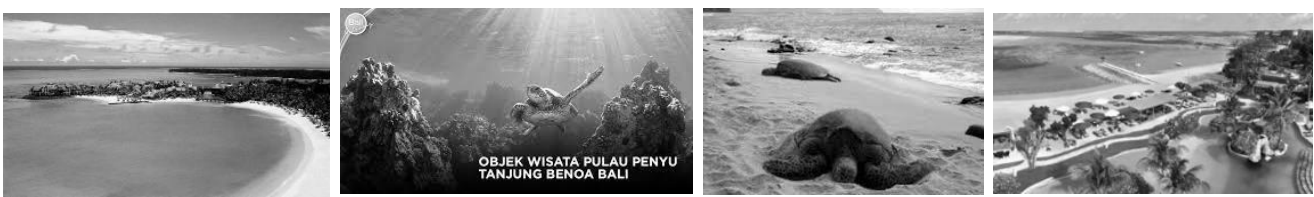

Gambar 4. Tanjung Benoa, Kuta Selatan-Bali

Setelah melakukan studi banding lapangan dan literatur dapat dibuat kesimpulan bahwa adanya kelebihan dan kekurangan dalam desain tersebut sehingga dapat menjadi acuan dalam merancang Wisata Bahari Tlocor ini.

\subsection{Lokasi Desain}

Lokasi Desain Eko-Wisata Bahari Tlocor ini terletak berada di kawasan Wisata Bahari Tlocor, di Desa Telocor, Tanjungsari, Kec Jabon, Sidoarjo. Di Wisata Bahari Tlocor ini terdapat Pulau Lusi (Lumpur Sidoarjo).

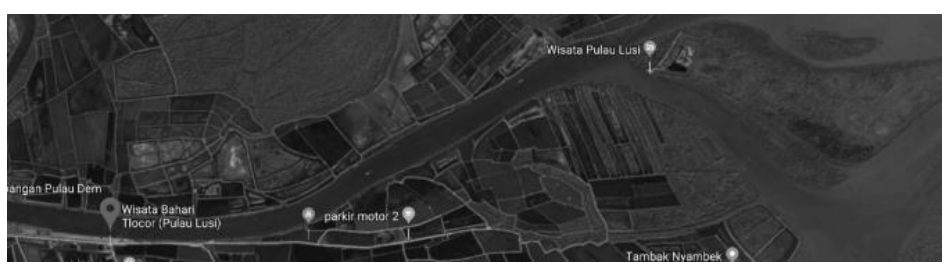

Gambar 5. Lokasi Wisata Bahari Tlocor

Berdasarkan rencana pengembangan kawasan Pulau Lusi, kawasan dibagi menjadi 3 zona, yaitu zona $\mathrm{A}$, zona $\mathrm{B}$, zona $\mathrm{C}$. Zona A merupakan zona untuk ekowisata, sehingga perancangan difokuskan pada zona A dengan luas terbangun yaitu $10 \%$ dari total luas keseluruhan pulau tersebut, dimana luas keseluruhan pulau ini yaitu 94 ha. Sedangkan zona B dan zona C merupakan zona konservasi. 


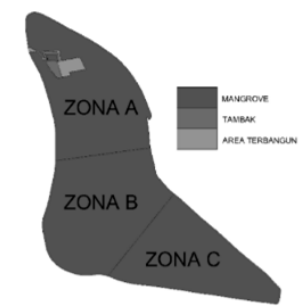

Gambar 6. Pembagian Zona Kawasan pada Pulau Lusi

\subsection{Konsep Desain}

\section{Tema : Arsitektur Berwawasan Lingkungan}

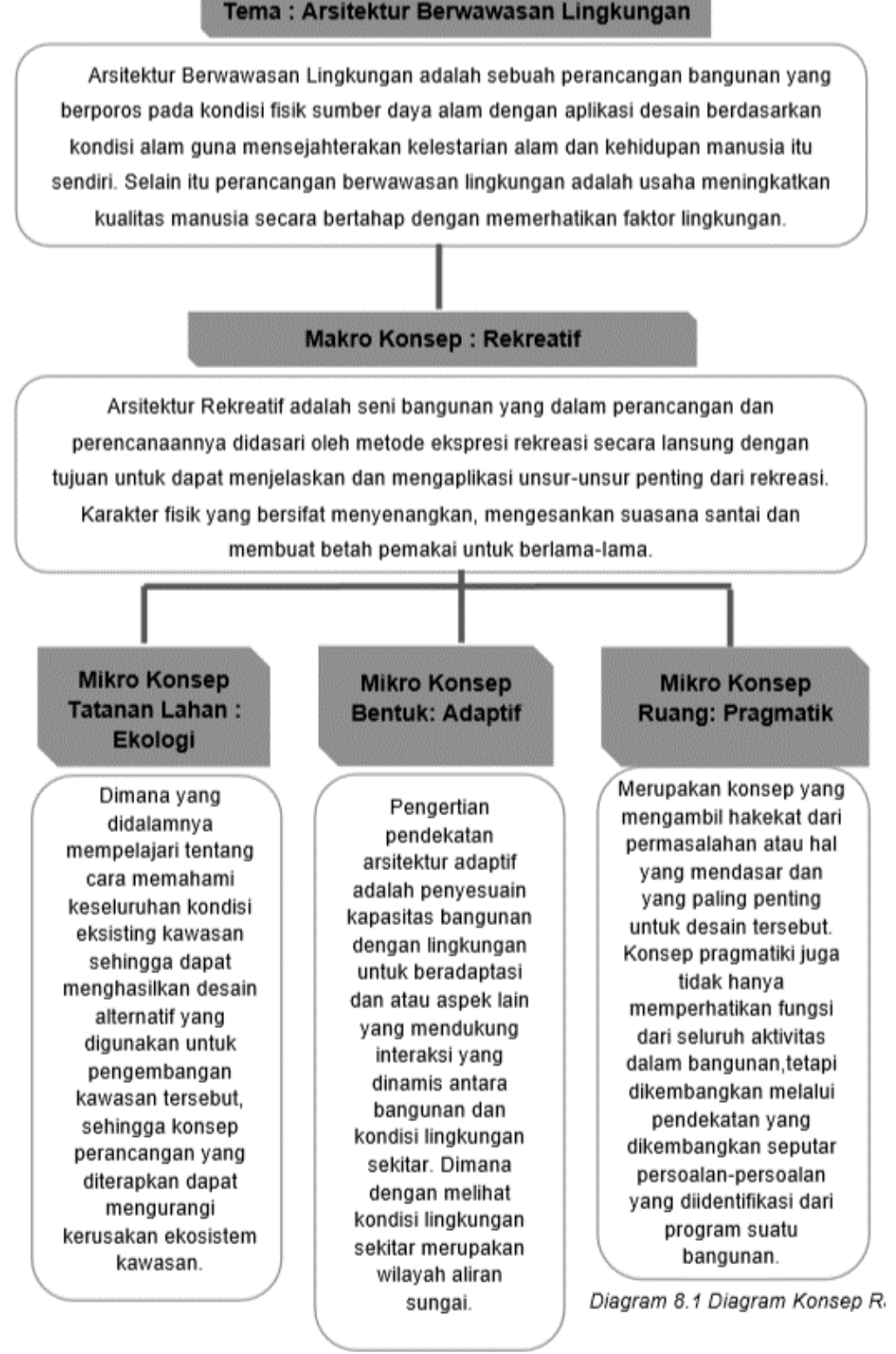

Gambar 7. Diagram penyusunan konsep desain

Hasil konsep desain ini terbagi menjadi 3 bagian, yaitu: (1) Transformasi Konsep Rancangan Tatanan Lahan; (2) Transformasi Konsep Rancangan Ruang; dan (3) Transformasi Konsep Rancangan Bentuk

\subsubsection{Transformasi Konsep Desain Tatanan Lahan}


Penataan tata letak massa bangunan dengan menerapkan konsep ekologi lanskap yang dimana pola kawasan diketahui bahwa di Pulau Lusi terdapat saluran untuk pengairan di sela-sela mangrove. Pola saluran air dimanfaatkan untuk digunakan sebagai pola jalur tracking dengan mengikuti bentuknya dan dilakukan penyesuaian dengan kawasan sehingga ekosistem Kawasan dapat terjaga.

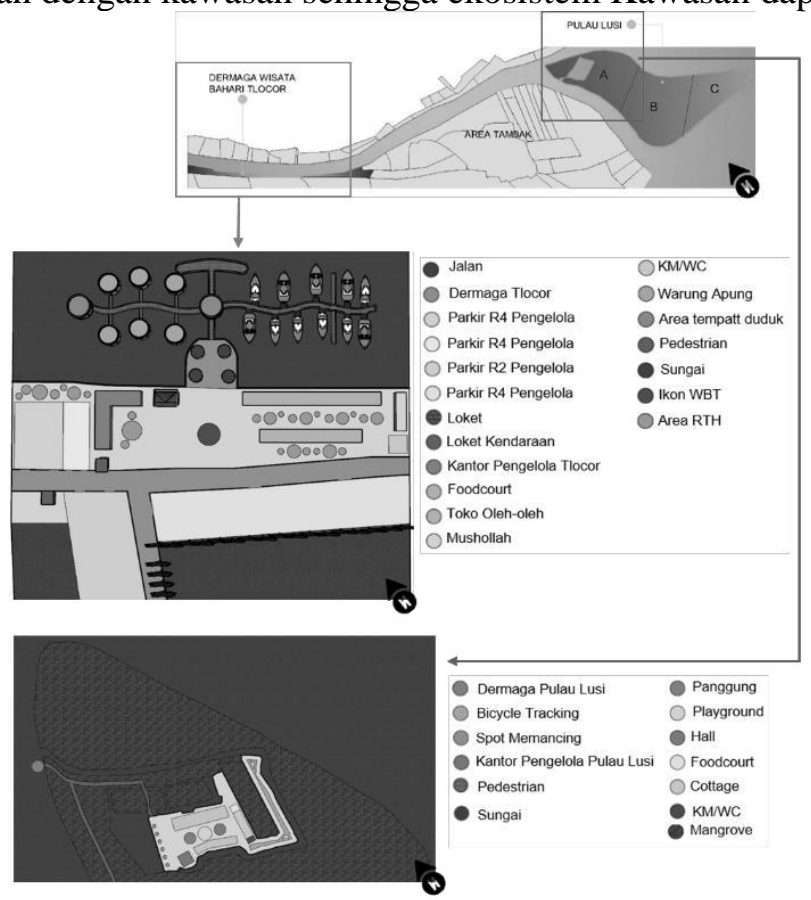

Gambar 8. Konsep Desain Tatanan Lahan

\subsubsection{Transformasi Konsep Rancangan Ruang}

Merupakan konsep yang mengambil hakekat dari permasalahan atau hal yang mendasar dan yang paling penting untuk desain tersebut. Konsep pragmatiki juga tidak hanya memperhatikan fungsi dari seluruh aktivitas dalam bangunan,tetapi dikembangkan melalui pendekatan yang dikembangkan seputar persoalan-persoalan yang diidentifikasi dari program suatu bangunan.
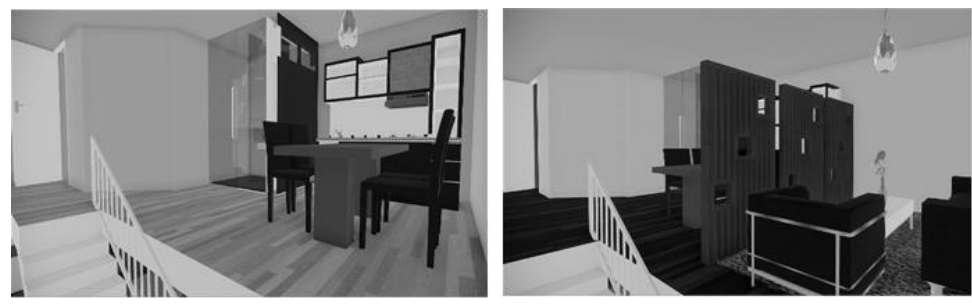

Interior Cottage Sumber: Dok. Pribad

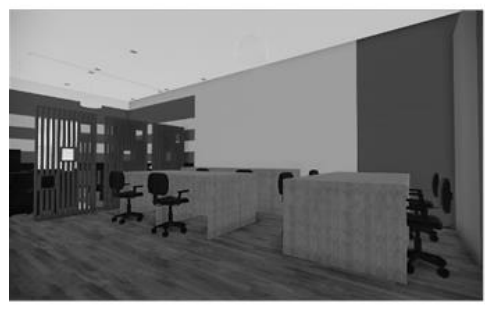

Interior Ruang Pengelola

Sumber: Dok. Pribadi

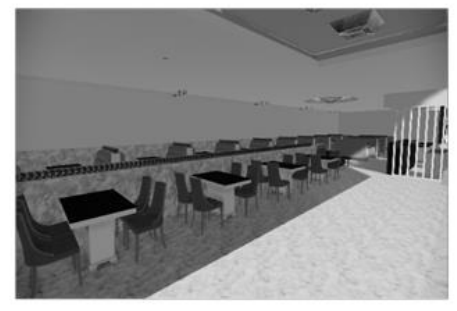

Interior Foodcourt Indoor

Sumber: Dok. Pribadi

Gambar 9. Konsep Rancangan Ruang

\subsubsection{Transformasi Konsep Rancangan Bentuk}


Rancangan bentuk arsitektur pada bangunan di Kawasan Pulau Lusi adalah bentuk bangunan yang adaptif yang dimana antara bangunan dan lingkungan sekitar saling dinamis antara bangunan dan kondisi lingkungan sekitar. Melihat Kawasan ini merupakan muara sungai. Dengan melihat hal tersebut, penyesuaian seperti atap memiliki overstek, teras yang beratap, jendela yang tidak terlalu lebar, dan terdapat ventilasi udara untuk penghawaan alami. Beberapa bagian pada bangunan dibuat terbuka agar pengunjung dapat merasakan dan melihat secara langsung kondisi ekosistem mangrove disekitar kawasan.

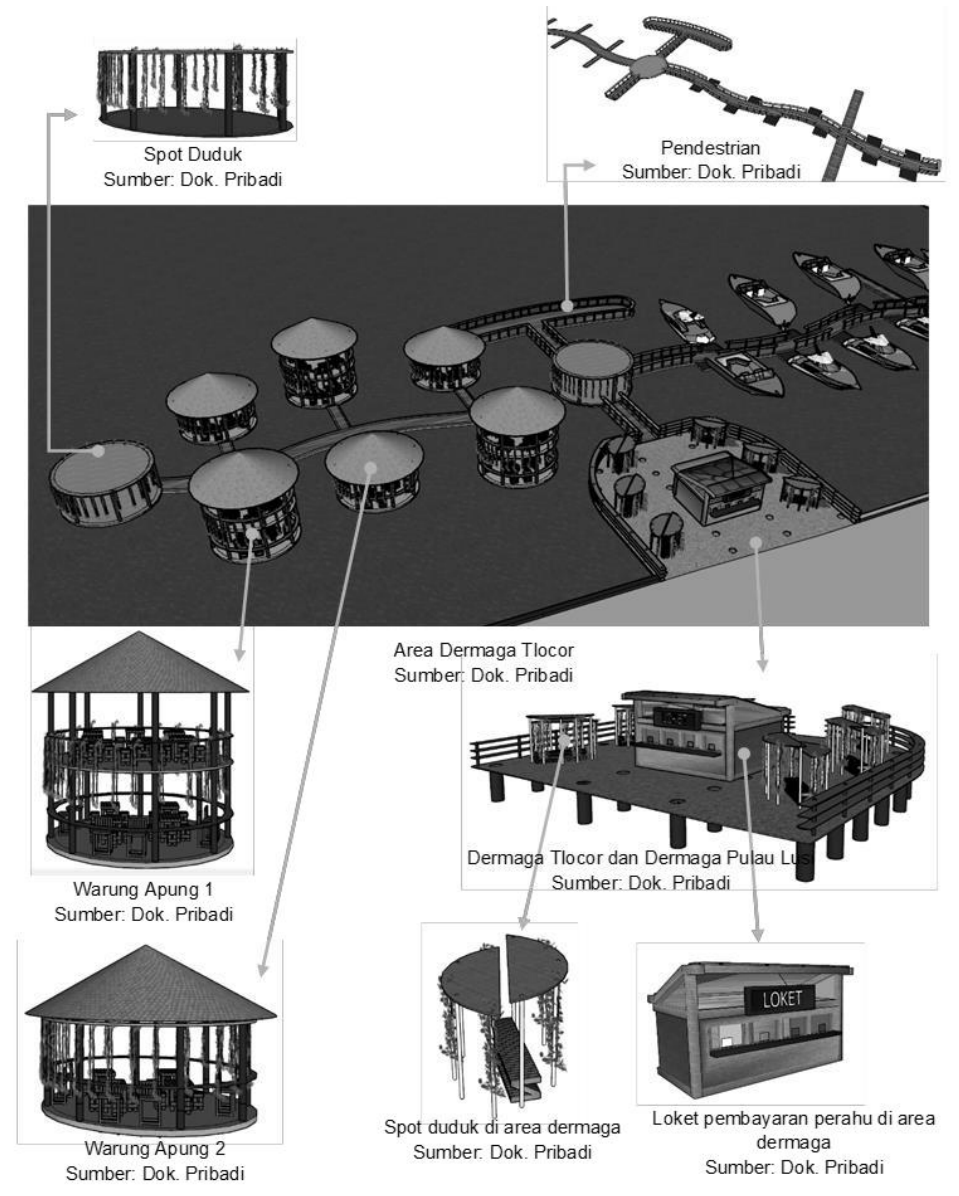

Gambar 10. Konsep Rancangan Bentuk

\section{Kesimpulan}

Perencanaan Wisata Bahari ini nantinya akan diarahkan untuk menggunakan tema arsitektur berwawasan lingkungan dengan konsep berupa arsitektur rekreatif. Konsep mikro ekologi yang dimana akan diterapkan pada tata lahan. Konsep mikro adaptif dari perairan sungai akan digunakan sebagai konsep bentuk bangunan, dan konsep mikro pragmatik untuk tata ruang, dimana nantinya akan sebagai jawaban dari permasalahan yang ada pada bangunan dan membuat pengunjung lebih nyaman. Tujuan dari proyek ini adalah untuk memberdayakan masyarakat setempat agar bertanggung jawab terhadap perencanaan dan pengelolaan lingkungannya selain itu mengupayakan agar masyarakat setempat dapat ikut berperan aktif dalam pengolahan pariwisata yang memanfaatkan kawasan lingkungannya.

\section{Referensi}

Adisasmita, Rahardjo. 2010/2013. Pembangunan Kawasan dan Tata Ruang. Yogyakarta. Graha Ilmu Sugandhy, Aca dan Rustam Hakim. 2007. Prinsip Dasar Kebijakan Pembangunan Berkelanjutan Berwawasan Lingkungan. Jakarta: Bumi Aksara

Pamungkas, Aji, dan Dian Rahmawati. 2017. Perencanaan Kawasan Pesisir Terpadu di Indonesia. Yogyakarta: Teknosain 